\title{
Developing leadership competencies for the knowledge society: the relevance of action learning
}

\section{H.J. van Niekerk}

Suritec (Pty.) Ltd, Stellenbosch, South Africa

herman@suritec.co.za

\section{Y. Waghid}

Department of Education Policy Studies, University of Stellenbosch, Stellenbosch, South Africa

yw@sun.ac.za

\section{Contents}

1. Introduction: leadership and knowledge workers

2. Emerging approaches to leadership

3. Middle-up-down approach

4. Developmental or servitude leadership

5. Action learning alternative in developing knowledge leadership

6. Research methodology

6.1 Focus group results

6.2 Correlation study results

7. Yenza leadership approach

8. Conclusion

9. References

Key words: Leadership; knowledge management; action learning

\section{Introduction: leadership and knowledge workers}

Leadership is an integral component of organizations and one that defines their direction and shapes their vision. Organizational leadership has always been an important aspect of organizational studies. The renewed interest in how leadership must develop to meet the challenges of the knowledge society has primarily been influenced by three developments during the last decade, namely the excellence movement of the 1980s, the emphasis on a resource-based approach to strategy, and the realization that the workplace is being transformed at a pace never experienced before. 
The renewed emphasis on leadership started with the excellence movement of the 1980s, led by the investigations of Peters and Waterman (1982), who highlighted leadership as one of the central themes if organizations want to be successful. Together with themes such as a bias for action, the need for constant innovation and regarding employees as a resource rather than a cost, it has set the direction for organizational development into a new century (Grieves 2000:349).

Two related issues that emerged during the 1990s were the emphasis on a resource-based approach to strategy, which emphasized the importance of intangible assets and the pace of change. Corporate strategists like Harrison (2003:10) view organizations as a bundle of resources, with knowledge and learning as the focus point of organizational resources that include financial resources, human resources, physical resources and general organizational resources. Kaplan and Norton $(2004: 4,13)$ claim that in the knowledge society as much as $75 \%$ of an organization's value is vested in its intangible assets, which are described as human capital, information capital and organization capital. Leadership is an important constituent of organization capital, which also includes culture, teamwork and knowledge management. Together with innovation, customer relationships and brand value, intangibles such as knowledge and intellectual assets are viewed as the drivers of future corporate wealth with leadership being included as a powerful latent capability of an organization (BSi 2003:26).

Concurrent with this emphasis on a resource-based strategy, it is also acknowledged that the world is changing at a pace never experienced before and that 'leadership styles and skills that may have worked in stable, predictable environments will be inadequate in an era of radical uncertainty' (Marquardt and Berger 2000:1). The net total of these inter-related developments is the realization that organizations need to learn how to adapt quickly to changing environments, with leadership playing a central role in achieving the desired change.

Antal, Lenhardt and Rosenbrock (2001:868) identify leadership as a primary barrier to organizational learning, while Thurbin (1995:95) and Garvin (2000:187) posit that leadership and managerial influences in the knowledge organization should receive specific attention if knowledge management programmes are to be successfully implemented. Similarly, Holsapple and Joshi (2000:239-241) identify four main managerial influences related to KM, namely (a) leadership in the management of knowledge, (b) coordinating the management of knowledge, (c) controlling the management of knowledge, and (d) measuring the management of knowledge. Likewise, Senge (1990:360) argues that leadership in learning organizations is both collective and highly individual. Leadership is an important agency for organizational learning. Creating organizational knowledge essentially evolves around people, and for organizational learning and knowledge management to be effective, organizations must adopt greater people-centric perspectives of knowledge (Nonaka and Takeuchi 1995:61; Wiig 1999:20).

Leadership therefore plays an important role in constructing organizational knowledge. However, traditional leadership styles and management methods based on command and control principles, that once were perceived to increase the competitiveness of an organization, have become a liability as these methods have not been found to offer competitive advantages to these organizations. Management's role and organizational leadership need to change to reflect these new realities and therefore require a move away from the command and control approach to a different style of leadership.

The two most common leadership styles in contemporary organizations are transactional and transformational. The former approach is very much present in traditional organizations and it involves the position of power of the leader to use followers for task completion. In other 
words, leaders help employees identify what must be done to achieve the desired results (Horner 1997:274). Transformational leadership searches for ways to help motivate employees to work towards long-term strategic goals instead of short-term self-interest and they inspire and motivate employees to achieve results greater than they had originally planned (Horner 1997:270).

Bukowitz and Williams (1999:351) argue that today's leaders must pay attention to environments rather than rules, coach rather than tell, ask the right questions rather than provide the right answers. The result is a more distributed decision-making system, in which all members can and must participate. They conclude that from a knowledge perspective, effective leadership hinges on an ability to grasp the value-creating potential of the organization's knowledge base. The leader must not only set strategy, but also communicate it in a compelling fashion. The shift from being the source of all knowledge to managing the network of how knowledge flows lies at the heart of this new emerging leadership. To address these challenges some leadership approaches, which are not yet clearly defined, are emerging and will now be explored.

\section{Emerging approaches to leadership}

The relevance and importance of a new 'emerging' leadership have been explored by Nonaka and Takeuchi (1995:156), Bennis (1999:4-6), Scholtes (1999:704-711), Gilley and Maycunich (2000:69) and Marquardt and Berger (2000). In contrast to transformational and transactional leadership styles, an 'emerging' leader is defined as one with a developmental leadership approach or 'servantship'. Developmental leaders help employees grow and develop without regard for their own selfish interests. Similarly, Horner (1997:277) posits that leadership is seen as a process in which leaders are not seen as individuals in charge of followers, but as members of a community of practice. The latter needs to display the following characteristics: (a) learning is fundamentally a social phenomenon; (b) knowledge is integrated in the life of communities that share values, beliefs, languages, and ways of doing things; (c) the process of learning and the process of membership in a community of practice are inseparable; (d) knowledge is inseparable from practice; (e) the ability to contribute to a community creates the potential for learning (Liebowitz 2000:7-8).

Stone, Russell and Patterson (2004:349) argue that there are many similarities between transformational and servant leadership, but that the main difference between transformational and servant leadership is based on a difference in focus. Transformational leaders tend to focus more on organizational objectives, while servant leaders focus more on people who are their followers. Leadership approaches are thus shifting from the individual command and control approach to a collective and collaborative approach. Three distinctive approaches to leadership are emerging, namely the middle-up-down approach, the developmental approach and an action learning approach.

\section{Middle-up-down approach}

Line management has a particular role to play in enabling organizational knowledge. Nonaka and Takeuchi (1995:232) argue that knowledge is primarily enabled by middle management and suggest the 'middle-up-down' approach that narrows the gap between the vision of the organization and grass roots reality. To embrace such an approach, a different organizational structure is required, namely the 'hypertext' organization. This structure combines a hierarchical and task force approach that promotes an organizational structure in which there 
is a continuous interplay between tacit and explicit knowledge (Nonaka and Takeuchi 1995:233). Similarly, MacNeil (2003:301) concludes that the role of the line manager as a facilitator of knowledge sharing in teams could make a significant contribution to maximizing core competence of learning in the organization.

This leadership approach, which one could also describe as the 'hypertext' approach, emphasizes the collective nature of leadership. Although the responsibility still largely lies with the leader to set the example, the shift is away from a command and control approach to one where every employee has a role to play in the organization. It is therefore not only the role of the leader which is changing, but also that of the (knowledge) worker. The power balance is shifting towards a situation where knowledge workers have a greater say and input into decisions.

\section{Developmental or servant leadership}

Organizations need to develop and promote leaders who realize that organizational renewal and competitive readiness are totally dependent on employees prepared for future challenges, continuous change, life-long learning and ever-increasing competition. These leaders are described as developmental leaders, leaders who are firstly characterized by servantship. Such leaders put employee needs, growth and development above their own interests, and inspire trust via their actions, beliefs and values placed on followers (Gilley and Maycunich 2000:62-65). Similarly, Sadler (2001:422-424) argues that in a learning organization, a leader has three functions, that of designer, steward and teacher. The essence of this kind of leadership is to design learning processes. Stewardship has to do with the long-term survival of the company and as a teacher the leader is continually helping people to see the bigger picture.

To be an effective leader in the 21 st century, eight key attributes are emerging which can be summarized as follows:

1. The ability to think in terms of systems and knowing how to lead systems (Gilley and Maycunich 2000:81; Marquardt and Berger 2000:1; Scholtes 1999:705; Senge 1990:343)

2. The ability to understand the variability of work in planning and problem solving (Gilley and Maycunich 2000:124; Scholtes 1999:708)

3. Understanding how we learn, develop and improve, and leading life-long learning and improvement (Bennis 1999:5; Marquardt and Berger 2000:1; Scholtes 1999:706)

4. Knowledge in generating and sustaining trust (Bennis 1999:4; Nonaka and Takeuchi 1995:156)

5. Understanding the interdependence and interaction between systems, variation, learning and human behaviour; knowing how each affects the other (Scholtes 1999:706; Senge 1990: 359)

6. Giving vision, meaning, direction and focus to the organization (Bennis 1999:6; Marquardt and Berger 2000:31; Scholtes 1999:708; Senge 1990:346)

7. The ability to integrate various methodologies for knowledge construction (Gilley and Maycunich 2000:124; Nonaka and Takeuchi 1995:156)

8. Comfort and confidence with technology and how it enables organizational performance and learning (Marquardt and Berger 2000:29).

A common feature emerging from these competencies is the emphasis that is placed on both individual and collective, or team learning. In a static world, the need to learn is not very great. But in an uncertain world, learning never ends. This approach requires that we need to 
revisit the way in which people acquire knowledge and the competencies required by knowledge workers and leaders. Horibe (1999:6) and Sadler (2001:426) argue that these new management challenges related to knowledge workers require the following:

1. Encouraging new knowledge to come forward

2. Tapping into everyone's knowledge

3. Managing knowledge you do not understand

4. Encouraging people to learn

5. Encouraging learning by asking challenging, awkward questions; by stimulating intellectual curiosity

6. Facilitating the learning of others by acting as coach or mentor.

A central element in being a developmental leader is the ability to communicate effectively and one's command of language. Communication is an essential element firstly to establish trust, which implies open, honest and direct communication. Secondly, developmental leaders must also be successful in communicating their organization's purpose and articulating the vision to enable employee support and involvement. A third important aspect of communication is a developmental leader's ability to ask relevant and pertinent questions, an aspect which the empirical research will focus on. This aspect in particular is highlighted by Seeley (2003:8) as an important step in facilitating change and creating a knowledgesharing culture. The examples set by the leaders of an organization are of particular importance. If managers start asking relevant questions, all employees will eventually begin to ask others for their expertise and insights. To enable such an approach, Seeley (2003:8) suggests the Knowledge Leadership Cue Card concept, namely, if you can influence the questions that managers and supervisors ask their staff, you can influence the importance placed on knowledge sharing by those employees.

Developmental leadership provides a possible approach in developing leaders for the knowledge society. These characteristics identified in the previous paragraphs need to be encouraged and nurtured.

\section{Action learning alternative in developing knowledge leadership}

An alternative to these new emerging leadership features described above is an action learning approach, which embodies many of these new and emerging leadership traits. Action learning has emerged as one of the most powerful and effective tools employed by organizations worldwide to develop and build their leaders. Action learning derives its power from the fact that it does not isolate any dimension from the context in which managers work, but rather develops the whole leader (Marquardt 2000:233).

The power of action learning as a leadership development framework has been realized since the early 1990s, but its impact within organizational context has only became visible during recent years. It was successfully used by General Electric in the early 1990s (Welch 2001:174-176), as well as by other organizations such as Citibank, Shell and Johnson \& Johnson, to develop their leaders (Dotlich and Noel 1998:19).

Marquardt (1999:4) describes action learning as 'both a process and a powerful programme that involves a small group of people solving real problems while at the same time focusing on what they are learning and how their learning can benefit each group member and the organisation as a whole'. Action learning's greatest value is arguably its capacity for developing individuals (leaders), teams and organizations to effectively respond to change. Dotlich and Noel (1998:192) posit that 'action learning provides companies with a tool to 
identify twenty-first century leaders' and provide numerous examples of how action learning has assisted organizations in helping their people to become aware of their command-andcontrol tendencies and to adopt more relevant leadership traits.

Action learning displays most of the characteristics that are required by emerging leaders as has been explored in previous paragraphs. Marquardt (2004:118) quotes action learning leadership development programmes which specifically develop global competencies such as adaptive thinking, building relations, inspiring trust, aligning the organization, fostering open and effective communication, demonstrating vision and focusing on quality and continuous improvement. Other important competencies, such as critical questioning and reflection, are also developed in knowledge leaders through an action learning approach.

A number of leading companies have used action learning as an approach to develop their leaders. This approach has shown to be highly successful and has resulted not only in developing effective leaders, but also in improving organizational performance. A quantitative research approach has subsequently been used to determine if there is a correspondence between organizations that are using action learning as a leadership development programme, and organizations that have successfully implemented knowledge management programmes.

\section{Research methodology}

The research methodology was based on a qualitative approach, which included a focus group discussion and a correlation study. Mouton (2001:113) states that a descriptive approach presents evidence of interesting and significant patterns in existing data. Following such an approach, a correlation study was done, using reports and primary data from an internationally reputable research organization, Teleos. This data were then compared with case studies available in literature. From this correlation patterns emerged from which significant conclusions could be made.

\subsection{Focus group results}

The focus group was held in July 2004 and consisted of nine senior and middle managers in the hospitality industry. They were, inter alia, presented with a list of five variables and were asked to discuss their strongest and weakest attributes. These variables were based on what emerged from the literature study and were used as a framework for the discussion with the focus group. Figure 1 is an analysis of the responses.

Figure 1 Managers’ responses to emerging attributes

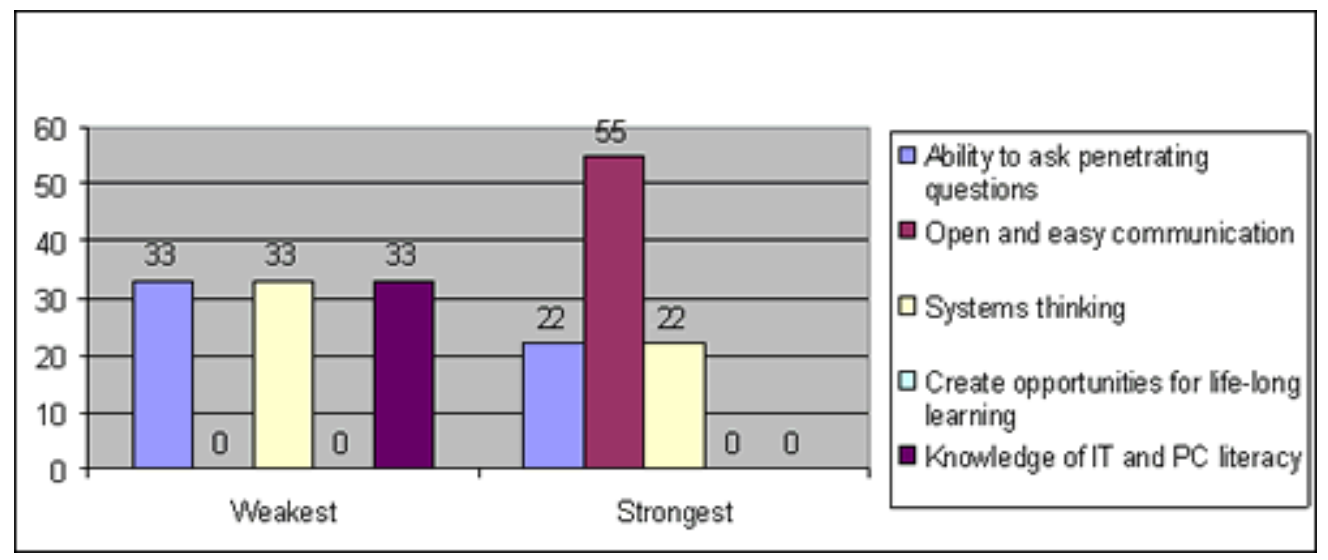


The results indicated that open and easy communication was the strongest attribute with 55\% of this sample group. However, the weakest attribute was equally divided between the ability to ask critical questions, to think in terms of systems, and a weak knowledge of IT and individual personal computer (PC) skills. Although the emergence of open communication as the strongest attribute is acknowledged, the weaker attributes are in the majority. This is an indication that managers are slow in making the transition to face the challenges of the new world of work.

\subsection{Correlation study results}

The Global Most Admired Knowledge Enterprises (MAKE) research programme, conducted by Teleos, annually releases a report to acknowledge organizations for their ability to utilize new as well as existing enterprise knowledge, and to deliver superior performance, in areas such as organizational creativity. The research is based on the Delphi technique and finalists are measured against eight knowledge performance dimensions that are the visible drivers of competitive advantage. These dimensions include, inter alia, the creation of a corporate knowledge culture, developing knowledge leaders and creating a learning organization (Chase 2002:1).

For the 2002 Global MAKE study, a total of 106 organizations were nominated of which 50 were selected as finalists. From this list of finalists, the top 20 organizations were selected as winners. The MAKE list of companies was subsequently evaluated against references and case studies of companies that had implemented action learning development programmes. These cases had been obtained from experts on action learning programmes, who had either done research on these companies, or had consulted to these companies. In other words, this evaluation compared companies that had embarked on action learning development programmes, and whose learning methodology and leadership development were based on action learning, with companies that were internationally recognized by the MAKE report as leading companies that had implemented knowledge management programmes. At least 13 of the 20 companies (65\%) have implemented action learning programmes and these are presented in alphabetical order in Table 1.

Table 1 MAKE finalists 1998-2002 (Chase 2002)

\begin{tabular}{|c|c|}
\hline $\begin{array}{l}\text { Global most admired } \\
\text { knowledge enterprises (MAKE) } \\
\text { Finalists 1998-2002 }\end{array}$ & $\begin{array}{l}\text { Case studies of companies applying action } \\
\text { learning principles }\end{array}$ \\
\hline Arthur Andersen/Accenture & $\begin{array}{l}\text { Dotlich and Noel (1998:93); Marquardt } \\
\text { (1999:84-85); Schwandt and Marquardt } \\
(2000: 143)\end{array}$ \\
\hline British Petroleum (BP) & Dixon $(2000: 14,24,38-39)$ \\
\hline Buckman Laboratories & Dixon (2000:15) \\
\hline Ernst and Young & http://www.partnersforlearning.com/clients.htm \\
\hline General Electric & $\begin{array}{l}\text { Boshyk (2000:50-53); Marquardt (1999:217- } \\
\text { 218); Welch (2001:173-175) }\end{array}$ \\
\hline Hewlett-Packard & Schwandt and Marquardt (2000:166-168) \\
\hline IBM & Boshyk (2000:76-90) \\
\hline McKinsey and Company & $\begin{array}{l}\text { Schwandt and Marquardt (2000: 157); Thurbin } \\
(1995: 9-12)\end{array}$ \\
\hline Nokia & Marquardt (2003:xiii) \\
\hline
\end{tabular}




\begin{tabular}{|l|l|} 
Royal Dutch/Shell & Dotlich and Noel (1998: 3-14; 42-46) \\
\hline Siemens & Boshyk (2000:140-151) \\
\hline US Government & Marquardt (2003:xiii) \\
\hline Xerox & Marquardt (2003:xiii); Thurbin (1995:9-12) \\
\hline
\end{tabular}

This descriptive research confirmed the claim that there was a strong correlation between action learning as a leadership development programme, albeit by different names, and companies that had successfully implemented knowledge management programmes. A total of $65 \%$ of the top 20 companies that instituted knowledge management programmes had also been using action learning. Furthermore, in research undertaken by Van Niekerk (2004:142), the relevance of action learning as a leadership programme developing these new competencies shows that 92\% (sample size was 120) of respondents indicated that action learning developed their leadership skills to a great or very great extent. Ninety-four per cent also indicated that action learning strongly develops continuous learning and critical thinking skills.

From the various research results presented in this article, it is evident that companies that had been applying action learning in their leadership development programme had a greater amount of success with the implementation of knowledge management programmes than those who did not. It has also been shown that individual managers had not yet completely made the transition to acquire the new skills that were required by a knowledge economy. Action learning-based leadership should therefore be an important consideration and driver in the implementation of knowledge management programmes.

The MAKE research did not include South African companies and the question could rightly be asked if an action learning approach would be relevant to the South African situation. The author strongly contends that this is the case as will be shown in the following section.

\section{Yenza leadership approach}

The spirit of African leadership closely relates to these new leadership traits that are emerging in a knowledge society. Within the African context, Mbigi (2004:40) identifies the servant leader, and proposes the following as key values in African leadership:

- Respect for the dignity of others

- Group solidarity: an injury to one is an injury to all

- Teamwork where none of us is greater than all of us

- Service to others in the spirit of harmony

- Interdependence. The most successful servant leaders are those who have become skilled empathetic leaders

- Persuasion, which is the clearest distinction between conventional authoritarian leadership styles and that of servant leadership.

In analogy to Human (1998:172), who uses the word Yenza (meaning 'action') in developing a strategic and change management framework, the Yenza leadership framework is proposed. The Yenza leadership framework embodies both the spirit of African leadership and developmental and change leadership which are required to enable learning and the creation of knowledge in learning organizations of the 21 st century. Such a framework emphasizes the importance of teamwork in which collaborative learning is valued, respect for others exists and where critical questioning is allowed in the spirit of open and respectful communication. These are the central constructs for adopting an alternative leadership 
approach suitable for the knowledge society and which will enable the construction of organizational knowledge and learning.

\section{Conclusion}

Zuber-Skerritt and Perry (2002:177) posit that action learning and action research are appropriate and effective methods for developing a person's managerial 'soft' skills, competencies and other attributes required by managers and leaders within the 21 st-century learning organization. Action learning intrinsically promotes most of those competencies that need to be nurtured in a developmental leader. These competencies, which include problemsolving, leadership development, systems thinking, collective learning, ability to ask questions, building relations and developing trust, are highly relevant to knowledge organizations. Action learning is used by a number of leading international organizations as a leadership programme and has already shown itself as a highly effective way of developing knowledge leaders in preparation for the knowledge society of the 21 st century. The Yenza leadership framework not only reflects the values important to the African spirit, but also operates simultaneously on the fault line of the Western and African divide. It bridges this divide and is likewise relevant to and suitable for developing leaders in the Africa context.

top

\section{References}

Antal, A.B., Lenhardt, U. and Rosenbrock, R. 2001. Barriers to organisational learning. In: Handbook of organizational learning and knowledge, by Dierkes, M., Antal, A.B., Child, J. and Nonaka, I (eds). Oxford: Oxford University Press 865-885.

Bennis, W. 1999. Five competencies of new leaders. Executive Excellence16(7):4-6.

Boshyk, Y. (ed.). 2000. Business driven action learning: global best practices. Houndmills, Basingstoke, Hampshire: Macmillan Business.

British Standards Institute. 2003. Measurements in knowledge management: guide to good practice. London: BSI. [British Standards Institute PD7502.]

BSi seeBritish Standards Institute.

Bukowitz, W.R. and Williams, R.L. 1999. The knowledge management field book. London: Pearson Education.

Chase, R.L. 2002. Global most admired knowledge enterprises. Teleos Report. [Online]. Available at http://www.knowledgebusiness.com (Accessed 24 June 2002).

Dixon, N. 2000. Common knowledge. Boston, MA: Harvard Business School Press.

Dotlich, D.L. and Noel J.L. 1998. Action learning: how the world's top companies are recreating their leaders and themselves. San Francisco, CA: Jossey-Bass.

Garvin, D.A. 2000. Learning in action: a guide to putting the learning organization to work. Boston, MA: Harvard Business School Press.

Gilley, J.W. and Maycunich A. 2000. Beyond the learning organization: creating a culture 
of continuous growth and development through state-of-the-art human resource practices. Cambridge, MA: Perseus Books.

Grieves, J. 2000. Introduction: the origins of organizational development. Journal of Management Development 19(5):345-447.

Harrison, J.S. 2003. Strategic management of resources and relationships: concepts and cases. New York: John Wiley.

Holsapple, C.W. and Joshi, K.D. 2000. An investigation of factors that influence the management of knowledge in organizations. Journal of Strategic Information Systems 9 (2/3):235-261.

Horibe, F.D.E. 1999. Managing knowledge workers: new skills and attitudes to unlock the intellectual capital in your organization. Toronto: John Wiley.

Horner, M. 1997. Leadership theory: past, present and future. Team Performance Management 3(4):270-287.

Human, P. 1998. Yenza: a blueprint for transformation. Cape Town: Oxford University Press.

Kaplan, R.S. and Norton, D.P. 2004. Strategy maps: converting intangible assets into tangible outcomes. Boston, MA: Harvard Business School Press.

Liebowitz, J. 2000. Building organizational intelligence: a knowledge management primer. Boca Raton, FL: CRC Press.

MacNeil, C.M. 2003. Line managers: facilitators of knowledge-sharing in teams. Employee Relations 25(3):294-307.

Marquardt, M.J. 1999. Action learning in action. Palo Alto, CA: Davies-Black.

Marquardt, M.J. 2000. Action learning and leadership. The Learning Organization 7(5): 233240.

Marquardt, M.J. 2004. Optimizing the power of action learning: solving problems and building leaders in real time. Palo Alto, CA: Davies-Black.

Marquardt, M.J. and Berger, N.O. 2000. Global leaders for the twenty-first century. Albany, NY: State University of New York Press.

Mbigi, L. 2004. Leadership - in search of an African spirit. Business in Africa Magazine:3842, March.

Mouton, J. 2001. How to succeed in your master's and doctoral studies: a South African guide and resource book. Pretoria: Van Schaik.

Nonaka, I. and Takeuchi, H. 1995. The knowledge-creating company: how Japanese companies create the dynamics of innovation. New York: Oxford University Press.

Peters, T.J. and Waterman, R.H. 1982. In search of excellence. New York: Warner Books. 
Sadler, P. 2001. Leadership and organisational learning. In: Handbook of organizational learning and knowledge, by Dierkes, M., Antal, A.B., Child, J. and Nonaka, I. (eds.). Oxford: Oxford University Press: 415-427.

Scholtes, P.R. 1999. The new competencies of leadership. Total Quality Management 10 (4/5):704-711.

Schwandt, D.R. and Marquardt, M.J. 2000. Organisational learning: from world-class theories to global best practices. Boca Raton, FL: St. Lucie Press.

Seeley, C.P. 2003. Subject matter expert: asking smart questions to shape your knowledge culture. KM Review. [Online]. Available www.melcrum.com (Accessed 23 March 2004).

Senge, P. 1990. The fifth discipline: the art and practice of the learning organization. London: Random House.

Stone, A.G., Russell, R.F. and Patterson, K. 2004. Transformational versus servant leadership: a difference in leader focus. The Leadership \& Organization Development Journal 25(4):349-361.

Thurbin, P.J. 1995. Leveraging knowledge: the 17-day program for a learning organization. London: Pitman.

Van Niekerk, H.J. 2004. Enabling organisational knowledge through action learning: an epistemological study. Unpublished $\mathrm{PhD}$ dissertation, Stellenbosch University.

Welch, J. 2001. Jack: what I've learned leading a great company and great people. London: Headline.

Wiig, K.M. 1999. Knowledge management: an emerging discipline rooted in a long history. [Online]. Available http://www/krii.com (Accessed 12 May 2001).

Zuber-Skerritt, O, and Perry, C. 2002. Action research within organizations and university thesis writing. The Learning Organization 9(4):171-179.

\section{Disclaimer}

Articles published in SAJIM are the opinions of the authors and do not necessarily reflect the opinion of the Editor, Board, Publisher, Webmaster or the Rand Afrikaans University. The user hereby waives any claim he/she/they may have or acquire against the publisher, its suppliers, licensees and sub licensees and indemnifies all said persons from any claims, lawsuits, proceedings, costs, special, incidental, consequential or indirect damages, including damages for loss of profits, loss of business or downtime arising out of or relating to the user's use of the Website. 
ISSN 1560-683X

Published by InterWord Communications for the Centre for Research in Web-based Applications, Rand Afrikaans University 